
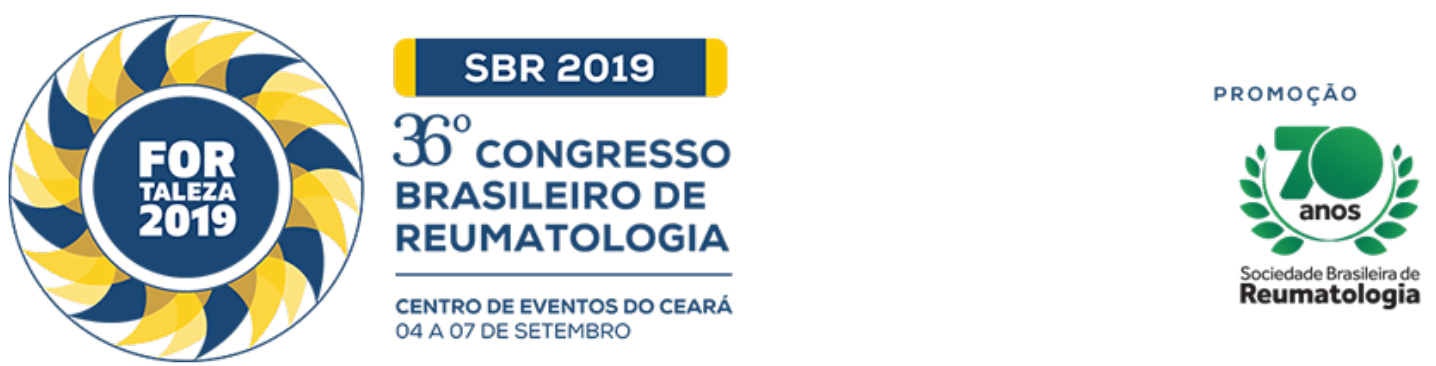

\title{
ANTI-TOPOISOMERASE 1 ANTIBODIES IN SYSTEMIC LUPUS ERYTHEMATOSUS
}

Carolina Ferreira (Hospital Universitário Evangélico Mackenzie, Curitiba, PR, Brasil), Fernanda Ribas Baracho (Hospital Universitário Evangéico Mackenzie, Curitiba, PR, Brasil), Vanessa Picceli (Hospital Universitário Evangélico Mackenzie, Curitiba, PR, Brasil), Carla Luchese de Almeida (Rheumatology Unit Hospital Universitário Evangélico Mackenzie, Curitiba, PR, Brasil), Thiago Alberto Fernandes Gomes dos Santos (Rheumatology Unit - Hospital Universitário Evangélico Mackenzie, Curitiba, PR, Brasil), Renato Nishihara (Faculdade Evangélica Mackenzie do Paraná, Curitiba, PR, Brasil), Thelma Laroca Skare (Rheumatology Unit - Hospital Universitário Evangélico Mackenzie, Curitiba, PR, Brasil)

\section{BACKGROUND}

Anti-topoisomerase-I (anti-Scl-70) is found in systemic sclerosis patients mostly in diffuse and aggressive forms of the disease. Anti-Scl-70 may be found in systemic lupus erythematosus (SLE) patients. Gussin et al. detected a prevalence of this autoantibody in $25 \%$ of 128 SLE patients associating its presence with disease activity, pulmonary arterial hypertension, glomerulonephritis and anti-dsDNA. Mahler et al. (5) found a prevalence of this autoantibody in $7.7 \%$ of 168 SLE patients, usually at low titers using ELISA test, and $0 \%$ using immunoassay.

\section{MATERIALS AND METHODS}

We studied anti-SCl-70 in a cohort of 94 Brazilian SLE patients. Disease activity was measured by SELENASLEDAI (Safety of Estrogens in Lupus National Assessment-SLE Disease Activity Index). Scl-70 was searched by ELISA commercial kit $\left(V_{i r g o}{ }^{T M}\right.$, Columbia, USA). Values above $20 \mathrm{U} / \mathrm{mL}$ were consider positive, according manufacturer.

\section{RESULTS}

Only two (2.1\%) patients were positive for anti-Scl-70, both at low titters ( $56 \mathrm{U} / \mathrm{mL}$ and $68 \mathrm{U} / \mathrm{mL}$ ). One of them was a 21 year old white male with arthritis, photosensitivity, malar rash and class 4 glomerulonephritis and with SLEDAI of 4 at time of blood collection. This patient had a recurrence of his glomerulonephritis six months later on. Another was a 48 year old afro descendant female with thrombocytopenia, skin and articular manifestations and with SLEDAI of 3. None of them had scleroderma features; the female patient had Raynaud phenomena.

\section{CONCLUSION}

In our sample of lupus patients, the prevalence of anti-Scl-70 was very low and the positive results were at low titer. 